\title{
A CRISE DA LEI PELA DESCRENÇA NO LEGISLATIVO
}

\author{
The law crisis for discretion in legislative
}

\author{
Pedro Henrique Nunes Fernandes ${ }^{1}$
}

RESUMO: Na teoria de Jeremy Waldron, temos a apresentação de maneiras de pensar a respeito da legislação como um modelo de governança dignificado e uma fonte de direito respeitável. Contudo, a legislação possui uma má-fama na filosofia jurídica e política que, na visão deste autor não poderia nem mesmo ser discutida, porque sequer há uma teoria normativa da legislação. Esta proposição seria aplicada ao nosso ordenamento? $O$ nosso processo legislativo não seria essa teoria normativa? $\mathrm{O}$ Brasil possui uma teorização e uma regulamentação positiva bastante para compor essa tão necessária teoria normativa. O que se pretende é o estabelecimento de um procedimento lógico, pelo qual se retira da referida premissa, uma conclusão que dela decorre diretamente. "Tratase de uma passagem do universal para o particular e para o singular. De um princípio geral, deduzimos outros menos gerais até fatos particulares".

Palavras-chave: Direito. Legislação brasileira. Sociedade.

ABSTRACT: In Jeremy Waldron's theory, we have the presentation of ways of thinking about legislation as a model of dignified governance and a source of respectable law. However, the legislation has a bad reputation in the legal and political philosophy that, in the view of this author could not even be discussed, because there is even a normative theory of the legislation. Would this proposition be applied to our ordering? Is not our legislative process such a normative theory? Does not Brazil have enough positive theorization and regulation to compose this much-needed normative theory? What is wanted is the establishment of a logical procedure, by which one withdraws from the said premise, a conclusion that comes directly from it. "It is a passage from the universal to the private and to the singular. From a general principle, we deduce others less general to particular facts.

Keywords: Right. Brazilian legislation. Society.

\section{INTRODUÇÃO}

Segundo Waldron "ninguém parece ter percebido a necessidade de uma teoria, de um tipo ideal que faça pela legislação o que o juiz-modelo de Ronald Dworkin, "Hércules", pretende fazer

\footnotetext{
I Mestrando do curso de Direito da Faculdade de Direito do Sul de Minas. E-mail: phnfernandes@hotmail.com.
}

2 SEVERINO, Antônio Joaquim. Metodologia do trabalho científico. 23. ed. São Paulo: Cortez, 2007. p. I05. 
pelo raciocínio adjudicatório3".

Nosso sistema poderia ser o representante dessa teoria ou desse tipo ideal tão necessário à legislação. O crédito e/ou descrédito da legislação perante a sua sociedade, tendo como base a falta ou a presença de um procedimento legislativo ou de pelo menos de uma teoria normativa, estaria na aplicação direta da legislação e na sua capacidade de se inserir no seio da sociedade. Pois, de nada adiantaria se respeitar a risca um procedimento, para no final se elaborar uma legislação inaplicável ou inconstitucional.

A legislação é o direito que compõe o material jurídico com que as pessoas comuns vêm a ter de lidar, porém, por vezes, o direto desenvolvido por juízes e tribunais, e não aquele feito pela legislatura, torna-se a questão central, mais interessante.

A própria legislatura diz que é possível se esquecer o que a lei foi o tempo todo, ou seja, que a partir de dado momento ela passará a ser de outra forma. Ela é mudada porque mudou o interesse do corpo legislador, por alteraram-se as pessoas que compunham esse corpo ou por qualquer outro motivo.

Não há nada mais volátil que a legislação. Não a nada mais passível da alteração do que a legislação; regras novas tomam o lugar de antigos preceitos ${ }^{4}$ de modo rápido e sem nenhuma explicação aparente sobre a alteração, sabe-se apenas da sua simples decretação.

A cada novo governo, nova remessa de leis são estabelecidas, fato esse tão comum na prática que, devido a sua repetição é até esperado, fazendo com que os destinatários da legislação, toda a sociedade, seja tratada como uma organização que deve ser administrada e gerida.

Como obter um consenso a respeito de um pensamento jurídico político com um corpo legislativo extremamente numeroso. Isso seria mais um obstáculo do que uma foram de se chegar a algo concreto. Podendo-se afirmar inclusive que, quanto maior a assembleia legislativa, mais baixo o nível médio de sabedoria e conhecimento dos legisladores 5 .

Não há como se estabelecer um sistema que atenda aos anseios de uma sociedade ou elaborar normas que reflitam as necessidades desta sociedade a partir da opinião discordante de mais de quinhentas pessoas.

\footnotetext{
${ }^{3}$ WALDRON, Jeremy. A dignidade da legislação. São Paulo: Martins Fontes, 2003.

${ }^{4}$ Idem.

5 WALDRON, Jeremy. A dignidade da legislação. São Paulo: Martins Fontes, 2003.
} 
A legislação é algo caro para uma sociedade e o tamanho da legislatura moderna, as práticas corruptivas de seus titulares, impedem a sua realização efetiva.

\section{A REPRESENTAÇÃo PELO LEGISLATIVO}

O poder legislativo na democracia nacional exerce a função a unção precípua de legislar, representando o povo e os Estados, juntamente com a competência para fiscalizar o executivo.

Assim, a forma como a função representativa é desempenhada afeta a qualidade da atuação legislativa e fiscalizatória. Idealmente, espera-se que o corpo de deputados federais eleitos desempenhe seu mandato em nome do povo. Isso envolve muitos aspectos, desde o conceito e abrangência da representação, os anseios e necessidades da sociedade, até a consciência do cidadão a respeito da titularidade do poder ${ }^{6}$.

A representação do povo pelo parlamentar, exige a consciência de que ele possuí relação com todo público que representa, e não somente com as categorias específicas que o elegeram. E, cabe ao povo a consciência de que todos aqueles que com o parlamente o representa e não somente aquele em que cada cidadão votou.

[...] a representação é uma via de mão dupla, que depende das características tanto do representante quanto do representado, salientando-se, no entanto, que a qualidade do mandatário do poder é consequência da qualidade daquele que lhe delega esse poder, visto que é o eleitor que, por meio do voto, escolhe seu representante ${ }^{7}$.

Vive-se uma cisão entre o parlamento e a sociedade, o que ameaça a democracia, pois, paira a sensação de que os parlamentares não são capazes de representar seus eleitores, verdadeiros titulares do poder, porém, desmotivados em relação a participação popular.

O poder legislativo está presente com frequência nas manchetes dos jornais, fazendo com que, até mesmo o fruto do seu trabalho, a legislação, acaba colocada em descrédito. É alvo de uma excessiva exposição, que enfatizam seus piores aspectos, incutindo na cabeça da população uma visão negativa do parlamento, nesse sentido.

O Poder Legislativo é, via de regra, alvo de superexposição na mídia, tendo seus aspectos falhos enfatizados pelos meios de comunicação. Isso contribui para impregnar o imaginário popular com o conteúdo divulgado e força o processo de

\footnotetext{
${ }^{6}$ CINNANTI, Cristina Jacobson Jácomo. A (des)confiança do cidadão no Poder Legislativo e a qualidade da democracia no Brasil. E-legis, Brasília, n. 6 , p. 84-95, Io semestre 20Ir. Disponível em <http://elegis.camara.leg.br> Acesso em 28. jun .2018.

7 Idem.
} 
construção de uma avaliação negativa do parlamento. Nessa avaliação, tende-se a generalizar os pontos fracos, que A (des)confiança do cidadão no Poder Legislativo e a qualidade da democracia no Brasil raramente são confrontados pela divulgação das ações relevantes do Legislativo. Há uma omissão da instituição no que tange a levar ao conhecimento da população a importância e os feitos desse Poder. ${ }^{8}$

A legislação é uma forma genuína de direito, é uma fonte de direito respeitável, porém, faltaria um modelo jurisprudencial capaz de compreender e demonstrar "a sua reinvindicação e as exigências que faz dos outros atores em um sistema jurídico"”.

Todos nós sabemos sobre a teoria da separação de poderes e a sua relação com os freios e contrapesos. Ocorre que, vivemos um momento em que a balança não está equilibrada, fazendo surgir alguns questionamentos:

Vivemos a supremacia de um poder sobre os demais?

Há um desequilíbrio? Quais as causas desse desequilíbrio?

Como proceder quando o fruto de um poder, ou seja, a lei, cai em descredito? Quais seriam as causas desse descrédito?

A população espera de seus legisladores ética e comprometimento com a Nação. Não basta viver em um país democrático, laureado com a conquista da liberdade de expressão, enquanto, lamentavelmente, a impunidade e o individualismo continuarem a dirigir as ações de muitos mandatários do poder, constituindo-se em uma ameaça ao exercício da cidadania e à credibilidade do povo nas instituições públicas. [...] $\mathrm{O}$ descrédito verificado em relação ao Parlamento contamina o próprio corpo profissional do Legislativo, indivíduos que, no papel de cidadãos, deploram a instituição em que trabalham e, no papel de servidores, envergonham-se por integrar os quadros de ente tão depreciado pela populaçãa ${ }^{10}$.

A legislação deve ser pensada como um modelo de governança dignificado e uma fonte de direito respeitável. Reconhece-se que ela possui uma má-fama na filosofia jurídica e política, porém sequer cabe essa discussão, tendo em vista que "não há uma teoria normativa da legislação”"

O que se apresenta, parece ser um convencimento já pré-estabelecido das pessoas, de que "há algo indecoroso em um sistema no qual uma legislatura eleita, dominada por partidos

\footnotetext{
${ }^{8}$ Ibidem.

9 WALDRON, Jeremy. A dignidade da legislação. São Paulo: Martins Fontes, 2003.

ro CINNANTI, Cristina Jacobson Jácomo. A (des)confiança do cidadão no Poder Legislativo e a qualidade da democracia no Brasil. E-legis, Brasília, n. 6 , p. 84-95, Io semestre 201ı. Disponível em http://elegis.camara.leg.br. Acesso em28. jun .2018.
}

II WALDRON, Jeremy. A dignidade da legislação. São Paulo: Martins Fontes, 2003 
políticos, que tomando suas decisões com base no governo da maioria”, tem a palavra final em questões de direito e princípios ${ }^{12}$.

Nos EUA, além de não se ter esse tão necessário modelo de legislação normativo, a atividade legislativa lá é apresentada como um modelo de troca de favores e negociatas ${ }^{13}$.

A legislação é apresentada como algo vazio para se viabilizar a revisão judicial. Seriam duas imagens postas lado a lado: a necessidade do julgamento e a má fama do legislador.

Contudo, ninguém se pergunta:

como seria construir um retrato róseo da legislaturas, que correspondesse, na sua normatividade, talvez na sua ingenuidade, e, certamente, na sua qualidade de aspiração, ao retrato dos tribunais" [...? $]^{14}$

Pode-se pensar em alguns pontos iniciais, como: um legislativo formado por várias mentes, seria um fundamento ou uma hipótese de legitimação para a lei elaborada. Contudo, o número excessivo de parlamentares impede a coesão e a possibilidade de se elaborar uma legislação digna, ou seja, capaz de refletir a necessidade da sociedade na qual ela está inserida.

Como seria um modelo ou compreensão da legislação que deveria ser realizado, apresentado e cultivado?

aquele no qual os representantes da comunidade unindo-se para estabelecer solene e explicitamente esquemas e medidas comuns, que se podem sustentar em nome de todos eles, fazendo-o de uma maneira que reconheça abertamente e respeite (em vez de ocultar) as inevitáveis diferenças de opinião e princípio entre eles ${ }^{15}$.

Coloca-se, portanto, o maior número de membros de um órgão legislativo como um obstáculo para a produção racional das leis.

Porém, contrária a essa ideia, tem-se teorias que buscam demonstrar que a quantidade de parlamentares não seria um problema à qualidade das leis produzidas; defendendo o parlamento como local apropriado para a produção legislativa digna.

A quantidade de membros e os conflitos que naturalmente surgem seriam características de uma assembleia popular, democrática, com prevalência para liberdade de expressão. Deve-se ter

\footnotetext{
${ }^{12}$ Idem.

${ }^{13}$ Ibidem.

${ }^{14}$ WALDRON, Jeremy. A dignidade da legislação. São Paulo: Martins Fontes, 2003.

is Ibidem
} 
um número razoável de membros, contrário ao nosso cenário atual, que sustenta mais de 550 pessoas.

Evoluindo no raciocínio, pode-se entender que não foi desenvolvida uma teoria normativa que estudasse a legislação e que essa própria legislação fosse a base para se subirem críticas e reprimir extravagancias.

Ocorre que no nosso país existe essa chamada teoria normativa. Possuímos um rigoroso processo legislativo, estudado e desenvolvido desde a graduação nas faculdades, (o que torna mais grave ainda a nossa situação), pois, ostentamos duas casas, várias comissões e a possibilidade de descartar projetos ainda no seu nascedouro. Nesse sentido, no nosso sistema o ingresso na sociedade de leis tidas como extravagantes ou que não representem a sociedade na qual ela está inserida ou para a qual ela foi feita é inadmissível.

O fato possuirmos condições de analisar detidamente a possibilidade ou não de um projeto tornar-se uma legislação inoperante ou inconstitucional, torna o nosso sistema um alvo visto de longe, pois temos todas as condições de sermos os mais sérios e eficazes nesse processo.

Contudo o mesmo processo que nos torna diretamente os exemplares nesse procedimento, acaba por ser o responsável pela sua malfadada fama. O congresso abarrotado, comissões sendo formadas e mudadas conforme o a cara política que se queira dar ou até mesmo conforme aquilo que se irá votar.

\section{A CRISE DA LEI FORMAL}

O descrédito da legislação perante o titular do poder é considerado um elemento histórico, que se desenvolve e aumenta durante o tempo ${ }^{16}$, o que gera a falta de efetivação dos direitos dos cidadãos diante poder estatal ${ }^{17}$.

É possível apontar focos responsáveis pela crise atribuída a legislação: o primeiro deles é

\footnotetext{
${ }^{16}$ CINNANTI, Cristina Jacobson Jácomo. A (des)confiança do cidadão no Poder Legislativo e a qualidade da democracia no Brasil. E-legis, Brasília, n. 6 , p. 84-95, Io semestre 20Ir. Disponível em http://elegis.camara.leg.br. Acesso em 28. jun. 2018.

${ }^{17}$ SPAGOLLAA Vânya Senegalia Morete. MORETE. Vivian Senegalia A Crise da Lei e seus Reflexos no Direito Administrativo: a Legalidade Questionada. UNOPAR Cient., Ciênc. Juríd. Empres., Londrina, v. I2, n. 2, p. 17-21, set. 2011 .
} 
que a lei não é capaz mais de ser uma expressão de justiça ${ }^{18}$.

Os autores responsáveis pelos projetos, sua tramitação, votação e aprovação tem se preocupado mais em fazer o seguir formalmente todo o processo legislativo estabelecido, e tão somente isso. Não se preocupam com a moralidade necessária para desenvolver essa atividade, tem-se somente "uma preocupação com o cumprimento das formalidades, que todo o restante (e tão necessária) hermenêutica constitucional parece secundária”"

A legislação não tem aplicabilidade pratica no seio da sociedade a qual será inserida ou, no mínimo estará em descompasso com a realidade social.

Nesse sentido,

A crise hoje vivenciada tem dupla ratio essendi: a 'dissintonia entre a lei e os anseios sociais' e a 'ineficiência da realização da justiça'. A lei como regra de conduta no seu amplo espectro de regulação das atividades humanas, tem-se revelado afastada das expectativas da comunidade. A justiça, por sua vez, se apresenta ineficiente e incapaz de cumprir o sumo postulado enunciado pelos jurisconsultos romanos de perpetua voluntas unicuique suum tribuendi (a vontade perpétua de dar a cada um o que é seu), quer pelas desigualdades que encerra, quer pela tardança da prestação jurisdicional, quer pela qualidade da resposta judicial ${ }^{20}$.

Percebe-se que a crise da lei como justiça refere-se desde o acesso à justiça até o seu descompasso com a vida social, cultural ou a realidade vivida pela população no pais ${ }^{21}$.

No segundo elemento responsável pela crise da legislação temos o entendimento de que a legislação não configura a expressão da vontade geral, tendo em vista a presença de uma representação particularizada dos parlamentares, que representam somente as classes voltadas aos seus próprios interesses políticos, àquelas as quais fazem parte e, em muitos casos, como sustentáculo em um processo de corrupção, não se preocupando com a verdadeira realidade

\footnotetext{
${ }^{18}$ BAPTISTA, P. Transformações do Direito Administrativo. Rio de Janeiro: Renovar, 2003. Disponível em: <http://bdpi.usp.br >. Acesso em: 28. out. 2018.

${ }^{19}$ BAPTISTA, P. Transformações do Direito Administrativo. Rio de Janeiro: Renovar, 2003. Disponível em 〈http://bdpi.usp.br> Acesso em: 27. out. 2018.

${ }^{20}$ FUX, Luiz. Uma nova visão do universo jurídico. Revista da EMERJ, v.4, n.15. p.143, 2001.

${ }^{21}$ BAPTISTA, P. Transformações do Direito Administrativo. Rio de Janeiro: Renovar, 2003. Disponível em 〈http://bdpi.usp.br> Acesso em: 27. out. 2018.
} 
$\operatorname{social}^{22}$.

A elaboração de normas voltadas para interesses particulares, agrava ainda mais o terceiro elemento responsável pelo descrédito legislativo, o grande número de normas em vigor e em tramitação.

Com esse grande arcabouço legislativo, os diplomas legais que deveriam ser um elemento fundamental para a regulação ou o disciplinamento das camadas sociais, tornam-se corriqueiros, entendidos como algo efêmero e sem a capacidade de imposição.

É necessária uma nova definição daquilo que se entende por norma, para permitir a todos os grupos sociais a identificação de suas necessidades, permitindo, novamente, que se tenha um sentimento de justiça entre todos que integram a comunidade ${ }^{23}$.

Temos a necessidade de uma legislação que seja mais eficaz, que possa estar disponível e atuar gerando efeitos, que permita à lei ser vista como um instrumento exclusivo para a consecução de mudanças sociais, o que pode ser atingido com a democratização do acesso aos textos legais em todos os níveis ${ }^{24}$.

\section{I A ATUAÇÃO DO PODER JUDICIÁRIO}

Dada a crise vivenciada pela descrença da sociedade no poder legislativo e naquilo que por ele é realizado, passa a ser destaque (ou necessária) a atuação dos demais poderes, em especial o judiciário, numa perspectiva entendida como ativista.

Contudo, é possível afirmar que:

[...] que a omissão do legislador democrático não é a causa do ativismo judicial do STF. Práticas ativistas dependem da existência de determinados elementos institucionais, políticos e/ou culturais e, muitas vezes, são respostas a esses estímulos ${ }^{25}$.

Nesse sentido Cortes liberais ou conservadoras podem ser responsáveis por julgamentos ativistas, pois acabam suas manifestações sendo vistas como tipos ideais, ou até mesmo formas de

${ }^{22}$ Idem.

${ }^{23}$ FUX, Luiz. Uma nova visão do universo jurídico. Revista da EMERJ, v.4, n.15. p.143, 2001.

${ }^{24}$ SOARES, Fabiana de Menezes. Legística e desenvolvimento: a qualidade da lei no quadro da otimização de uma melhor legislação. Revista da Faculdade de Direito da UFMG. Be I24 lo Horizonte, no ${ }^{\circ}$ 50, p. I24-I42, jan. - jul., 2007. Disponível em <www.direito.ufmg.br/revista. Acesso em 23. out. 2018.

${ }^{25}$ LEITE, Glauco Salomão. Inércia Legislativa e Ativismo Judicial: A Dinâmica da Separação dos Poderes na Ordem Constitucional Brasileira. Direito, Estado e Sociedade n.45 p. io a 31 jul/dez 2014. Disponível em <www.egov.ufsc.br> Acesso em: 28. out. 2018. 
representação ${ }^{26}$.

Ativismo judicial é uma expressão desenvolvida nos Estados Unidos, empregada na qualificação da atuação da Suprema Corte, principalmente durante os anos 1954 e 1969, período no qual ocorreu uma mudança na aplicação de inúmeras práticas políticas nos Estados Unidos, que foram conduzidas por uma jurisprudência progressista, principalmente no quando eram tratadas matérias relacionadas a direitos fundamentais. As transformações foram implementadas sem a participação do Congresso ou, ao menos, um decreto presidencial; o que gerou uma reação conservadora, assumindo a expressão ativismo judicial uma conotação negativa ${ }^{27}$.

Não está o ativismo judicial ligado ao conteúdo da decisão, pois uma decisão ativista não é necessariamente equivocada, mas que em uma determinada ordem constitucional fatores como os acima relatados fizeram com que decisões dessa natureza, com um ativismo judicial, fossem tomadas. Não se pode entendê-lo sempre como sinônimo de abuso, excesso ou arbítrio ${ }^{28}$.

Entende-se que a ordem constitucional pode não só estimular, como exigir posturas ativistas do Poder Judiciário em determinadas circunstâncias. Nessa perspectiva, a redução metodológica do ativismo judicial a problemas de interpretação jurídica acabaria minimizando-o enquanto categoria funcional relevante para se analisar o papel institucional das Cortes. Se se entende que, por mais protagonista que venha a ser, uma Corte Suprema jamais poderá simplesmente ocupar o espaço legítimo do sistema político, e se o ativismo judicial, numa abordagem institucional, pretende realçar precisamente a dinâmica de atuação entre os poderes, então o ativismo judicial não deve ser analisado exclusivamente como um problema de interpretação jurídica ${ }^{29}$.

O ativismo é um fenômeno complexo, porém, pode ser verificado em qualquer atuação judicial, suprimindo vazios, fiscalizando e garantindo que as omissões legislativas não gerem inconstitucionalidades e falta de efetivação de direitos. No direito positivo temos a previsão do mandado de injunção e da ação direta de inconstitucionalidade por omissão, que "pode ser

\footnotetext{
${ }^{26}$ Idem.

27 BARROSO, Luís Roberto. constituição, democracia e supremacia judicial: constituição, democracia e supremacia judicial. RFD- Revista da Faculdade de Direito- UERJ, v. 2, n. 21, jan./jun. 20I2. Disponível em <www.e-publicações.uerj.br> Acesso em: 28. out. 2018.
}

${ }^{28}$ LEITE, Glauco Salomão. Inércia Legislativa e Ativismo Judicial: A Dinâmica da Separação dos Poderes na Ordem Constitucional Brasileira. Direito, Estado e Sociedade n.45 p. Io a 31 jul/dez 2014. Disponível em <www.egov.ufsc.br> Acesso em: 28. out. 2018.

29 Idem. 
interpretada como uma desconfiança do constituinte em relação ao futuro legislador ordinário, que seria o encarregado de disciplinar os dispositivos constitucionais que exigiam sua intermediação" ${ }^{30}$.

[...] diante da eficácia limitada de preceitos constitucionais que exigiam norma integradora, o STF também produzia decisões ineficazes. O estado de anomia, portanto, subsistia. Porém, ao se promover uma guinada em sua jurisprudência, a Corte firmou sua competência para suprir o vazio normativo, permitindo o exercício do direito subjetivo, inicialmente no caso concreto. $\mathrm{O}$ ápice desse movimento se deu com o reconhecimento da eficácia erga omnes das decisões em mandado de injunção, perfazendo um ciclo que eleva os poderes do STF, afastando-o, cada vez mais, da imagem do "legislador negativo".

Pode-se apontar precedentes da jurisprudência nacional, de postura ativista, expressos pelo STF, em diferentes linhas de decisão, como a aplicação direta da Constituição a situações não expressamente contempladas em seu texto e independentemente de manifestação do legislador ordinário, como se passou

[...] em casos como o da imposição de fidelidade partidária e o da vedação do nepotismo; a declaração de inconstitucionalidade de atos normativos emanados do legislador, com base em critérios menos rígidos que os de patente e ostensiva violação da Constituição, de que são exemplos as decisões referentes à verticalização das coligações partidárias e à cláusula de barreira; a imposição de condutas ou de abstenções ao Poder Público, tanto em caso de inércia do legislador - como no precedente sobre greve no serviço público ou sobre criação de município - como no de políticas públicas insuficientes, de que têm sido exemplo as decisões sobre direito à saúde ${ }^{31}$.

Tais hipóteses podem ser entendidas como aquelas capazes de distanciar os responsáveis pela decisão de sua função típica, a aplicação do direito vigente, levando-os à de criação do próprio direito. O que se configura como uma escolha, ou seja, o ativismo é uma atitude proativa que visa interpretar a constituição com a expansão do seu alcance.

No caso do Brasil temos a presença desta atitude em situações de "retração do Poder Legislativo”, quando há um descompasso entre a classe política e a sociedade civil, gerando

${ }^{30}$ LEITE, Glauco Salomão. Inércia Legislativa e Ativismo Judicial: A Dinâmica da Separação dos Poderes na Ordem Constitucional Brasileira. Direito, Estado e Sociedade n.45 p. ro a 31 jul/dez 2014. Disponível em <www.egov.ufsc.br〉 Acesso em: 28. out. 2018.

${ }^{31}$ BARROSO, Luís Roberto. constituição, democracia e supremacia judicial: constituição, democracia e supremacia judicial. RFD- Revista da Faculdade de Direito- UERJ, v. 2, n. 2I, jan./jun. 20I2. Disponível em <www.e-publicações.uerj.br〉 Acesso em: 28. out. 2018. 
impedimentos para o atendimento das demandas sociais de modo efetiva.

Contudo, tal prática não é isenta de críticas, essa expansão judicial, com influência direta na vida social, configuraria uma violação das separações das funções, nesse sentido:

Juízes e membros dos tribunais não são agentes públicos eleitos. Sua investidura não tem o batismo da vontade popular. Nada obstante isso, quando invalida atos do Legislativo ou do Executivo ou impõe-lhes deveres de atuação, o Judiciário desempenha um papel que é inequivocamente político. Essa possibilidade de as instâncias judiciais sobreporem suas decisões às dos agentes políticos eleitos gera aquilo que em teoria constitucional foi denominado de dificuldade contramajoritária. A jurisdição constitucional e a atuação expansiva do Judiciário têm recebido, historicamente, críticas de natureza política, que questionam sua legitimidade democrática e sua suposta maior eficiência na proteção dos direitos fundamentais ${ }^{32}$.

Paralela a estas considerações, apresentam-se críticas de cunho ideológico, que acreditam ser o Judiciário uma instância conservadora, "responsável pelas distribuições de poder e de riqueza na sociedade", uma perspectiva que enxerga a judicialização como uma reação das elites tradicionais contra a democratização, um antídoto contra a participação popular e a política majoritária ${ }^{33}$.

No nosso ordenamento a responsabilidade pela interpretação da constituição e a definição da atuação cabe aos três poderes. Contudo, inevitavelmente, diante de divergências, compete ao judiciário a decisão final.

Ocorre que essa primazia não significa,

que toda e qualquer matéria deva ser decidida em um tribunal. Para evitar que o Judiciário se transforme em uma indesejável instância hegemônica, a doutrina constitucional tem explorado duas ideias destinadas a limitar a ingerência judicial: a de capacidade institucional e a de efeitos sistêmicos. Capacidade institucional envolve a determinação de qual Poder está mais habilitado a produzir a melhor decisão em determinada matéria. Temas envolvendo aspectos técnicos ou científicos de grande complexidade podem não ter no juiz de direito o árbitro mais qualificado, por falta de informação ou de conhecimento específico. Também o risco de efeitos sistêmicos imprevisíveis e indesejáveis podem recomendar uma posição de cautela e de deferência por parte do Judiciário. O juiz, por vocação e treinamento, normalmente estará preparado para realizar a justiça do caso concreto, a microjustiça, sem condições, muitas vezes, de avaliar o impacto de suas decisões sobre um segmento econômico ou

32 BARROSO, Luís Roberto. constituição, democracia e supremacia judicial: constituição, democracia e supremacia judicial. RFD- Revista da Faculdade de Direito- UERJ, v. 2, n. 2I, jan./jun. 2or2. Disponível em <www.e-publicações.uerj.br> Acesso em: 28. out. 2018.

33 Idem. 
sobre a prestação de um serviço público ${ }^{34}$.

O Direito possui métodos específicos e próprios para argumentar, o que exige conhecimento técnico e treinamento específico, na maioria das vezes não estendido à generalidade das pessoas. Nesse sentido judicialização poderia configurar uma "elitização do debate e a exclusão dos que não dominam a linguagem" 35 .

É possível apontar Institutos como audiências públicas, amicus curiae e entidades da sociedade civil como titulares do direito de propositura de ações diretas, que podem amenizar, mas não eliminar tal problema. Ocorre que, do outro lado, transferir o debate público para o Judiciário politiza excessivamente dos tribunais, permitindo que se dê lugar a sentimentos em um ambiente que deve ser presidido pela razão.

$\mathrm{Na}$ via paralela, processos contra parlamentares passam a tramitar nas manchetes de jornais, fazendo com que juízes substituam a racionalidade da argumentação jurídica por esse campo de embates próprios da discussão parlamentar, movida por visões políticas contrapostas e concorrentes.

A amplitude da jurisdição constitucional, da judicialização de questões sociais, morais e políticas, bem como, em algum grau, de ativismo judicial, podem ser apontados como traços marcantes do constitucionalismo contemporâneo e da ascensão institucional do Poder Judiciário.

Apesar da descrença no legislativo, deve-se cuidar para que as decisões judiciais não sejam prolatadas exorbitando de suas capacidades institucionais e limitando impropriamente o debate público, para que juízes e tribunais não se transformem em uma instância hegemônica, comprometendo a legitimidade democrática de sua atuação.

Não estando em discussão direitos fundamentais ou a preservação dos procedimentos democráticos, devem os juízes e tribunais devem acatar as escolhas feitas pelo legislador, ainda que esteja patente a descrença do titular do poder, abstendo-se de sobrepor a eles sua própria valoração política. Por fim, deve-se permitir ouvir os movimentos sociais e os canais de expressão da sociedade, pois o poder emana do povo.

34 BARROSO, Luís Roberto. constituição, democracia e supremacia judicial: constituição, democracia e supremacia judicial. RFD- Revista da Faculdade de Direito- UERJ, v. 2, n. 2I, jan./jun. 2or2. Disponível em <www.e-publicações.uerj.br> Acesso em: 28. out. 2018.

35 Idem. 


\section{CONCLUSÃo}

A legislação, representação do povo e expressão da sua vontade, por causa da atuação precária dos responsáveis pela sua elaboração, caiu em descrédito.

A função do juiz, que já se entendeu como aquela responsável por reproduzir o que estava na lei, sem uma função criadora, passou a exigir um papel criativo.

A legislação é um modelo de governança dignificado e uma fonte de direito respeitável, fruto de um processo legislativo que, no Brasil, representa uma teoria normativa positivada o bastante para se estabelecer um procedimento lógico, eficaz, que não poderia produzir um diploma inaplicável ou inconstitucional.

Porém problemas enfrentados para se respeitar essa teoria normativa, bem como, a atuação descompromissada e corruptiva dos parlamentares, geram críticas à legislação e favorecem a supervalorização da jurisdição.

\section{REFERÊNCIAS BIBLIOGRÁFICAS}

BARROSO, Luís Roberto. constituição, democracia e supremacia judicial: constituição, democracia e supremacia judicial. RFD- Revista da Faculdade de Direito- UERJ, v. 2, n. 2I, jan./jun. 2012. Disponível em <www.e- publicações.uerj.br> Acesso em 28. out. 2018.

CINNANTI, Cristina Jacobson Jácomo. A (des)confiança do cidadão no Poder Legislativo e a qualidade da democracia no Brasil. E-legis, Brasília, n. 6 , p. 4-95, Iํ semestre 201r. Disponível em http://e-legis.camara.leg.br. Acesso em 28. Jun.2018.

DWORKIN, Ronald. Uma questão de princípio. São Paulo: Martins Fontes,2005.

FUX, Luiz. Uma nova visão do universo jurídico. Revista da EMERJ, v.4, n.15. p.I43, 2001.

LEITE, Glauco Salomão. Inércia Legislativa e Ativismo Judicial: A Dinâmica da Separação dos Poderes na Ordem Constitucional Brasileira. Direito, Estado e Sociedade n. 45 p. Io a 31 jul/dez 2014. Disponível em <www.egov.ufsc.br $>$ Acesso em 28. Out. 2018.

MOREIRA, Herivelto; CALlEFE, Luiz Gonzaga. Metodologia da Pesquisa para o professor pesquisador. 2. ed. Rio de Janeiro: Lamparina, 2008.

SEVERINO, Antônio Joaquim. Metodologia do trabalho científico. 23. ed. São Paulo: Cortez, 2007.

SOARES, Fabiana de Menezes. Legística e desenvolvimento: a qualidade da lei no quadro da otimização de uma melhor legislação. Revista da Faculdade de Direito da UFMG. Belo Horizonte, no 50, p. 124-I42, jan. - jul., 2007. Disponível em <www.direito.ufmg.br/revista〉. Acesso em 28. Jun. 
2018.

SPAGOLlAA. Vânya Senegalia. Morete MORETE, Vivian Senegalia. A Crise da Lei e seus Reflexos no Direito Administrativo: a Legalidade Questionada. UNOPAR Cient., Ciênc. Juríd. Empres., Londrina, v. 12, n. 2, p. 17-21, set, 2011.

TATE. C. Neal e VALLINDER, Torbjorn. The Global Expansion of Juducial Power. New York. New York University Press, 1995.

WALDRON, Jeremy. A dignidade da legislação. São Paulo: Martins Fontes,2003. 